\title{
Gastric duplication 20 years after a partial distal gastrectomy: a case report and review of literature
}

This article was published in the following Dove Press journal:

Therapeutics and Clinical Risk Management

Yun Feng

Jin-Ning Ye

Chuang-Qi Chen

Xin-Hua Zhang

The Center for Gastrointestinal Surgery, The First Affiliated Hospital of Sun Yatsen University, Guangzhou, 510080 ,

People's Republic of China
Correspondence: Xin-Hua Zhang

The Center for Gastrointestinal Surgery,

The First Affiliated Hospital of Sun Yat-sen

University, \#58, Zhongshan 2nd Road,

Guangzhou 510080, People's Republic of

China

Email zhangxh_sysu@I63.com

\begin{abstract}
Gastric duplications are the least common gastrointestinal duplications, especially in adults. Duplication cyst with an accessory pancreatic lobe is extremely rare and is even more uncommon in the setting of polysplenia. No gastric duplication after partial gastrectomy has been reported. We present a 41-year-old male diagnosed with gastric duplications with an accessory pancreatic lobe and polysplenia. Another characteristic of this case is partial gastrectomy 20 years ago without the discovery of duplication cysts. The gastric duplications, accessory pancreatic lobe and accessory spleen were successfully resected.
\end{abstract} Keywords: gastric duplication, polysplenia, accessory pancreatic lobe, gastrectomy, adult

\section{Background}

Duplication cysts are rare congenital abnormalities which can affect any part of the alimentary tract. Most of them are identified in childhood. Gastric duplications are the least common gastrointestinal duplications, especially in adults. Duplication cyst with an accessory pancreatic lobe is extremely rare and is even more uncommon in the setting of polysplenia. No gastric duplication after partial gastrectomy has reported.

\section{Case presentation}

The patient was 41-year-old male with a previous medical history of distal partial gastrectomy for treating gastric ulcer in another hospital 20 years before. He came to our hospital with epigastric discomfort and distention for 3 years. The CT scan in our hospital showed there were bilateral cystic lesions in the abdominal cavity. The left lesion was subphrenic and $26.0 \mathrm{~cm} \times 14.0 \mathrm{~cm} \times 14.0 \mathrm{~cm}$ in size. And right lesion was subheptic and $18.0 \mathrm{~cm} \times 14.0 \mathrm{~cm} \times 13.0 \mathrm{~cm}$ in size. These lesions were probably congenital cyst, foregut duplication or mesenteric cyst. Two round structures were anterior and posterior to the left cystic lesion and their densities were similar to spleen. No abnormality was found in pancreas or pancreatic vessel. The CT image is shown in Figure 1. The CT scan demonstrated normal structure of other alimentary organs. Only anastomotic inflammation and post-gastrectomy (Billroth II) were found by gastroscopy (Figure 2).

After the multidisciplinary discussion with the radiologists and pathologists, the patient was diagnosed with benign cystic lesions. The patient underwent laparotomy. The left retroperitoneal lesion was about $25 \mathrm{~cm} \times 20 \mathrm{~cm}$, and the right one was about $20 \mathrm{~cm} \times 18 \mathrm{~cm}$ (Figure 3). A smaller hyaline cystic lesion of $6 \mathrm{~cm} \times 6 \mathrm{~cm}$ in size was also found in the sigmoid mesocolon. These three cystic lesions were completely resected (Figure 4). The patient had two separate spleens and an 

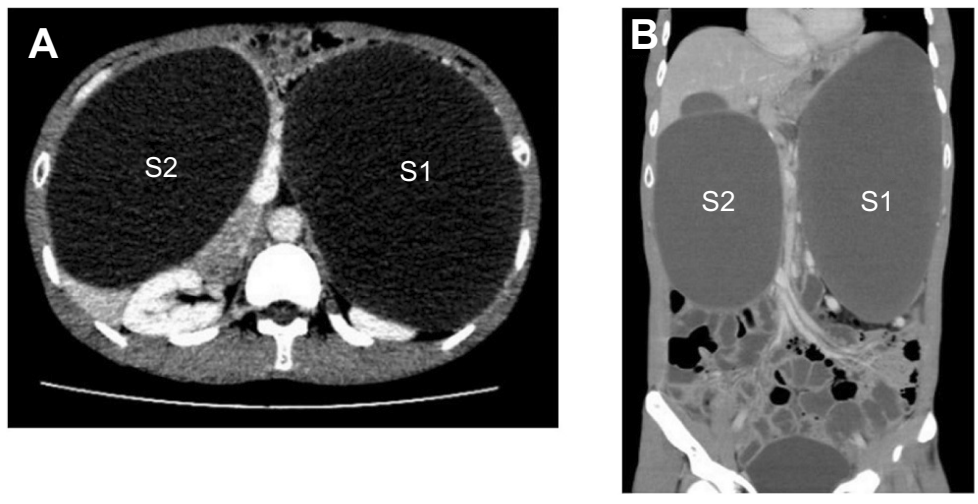

Figure I CT image of the left (SI) and right (S2) gastric duplication cysts. (A) Transveral plane; (B) coronal plane.
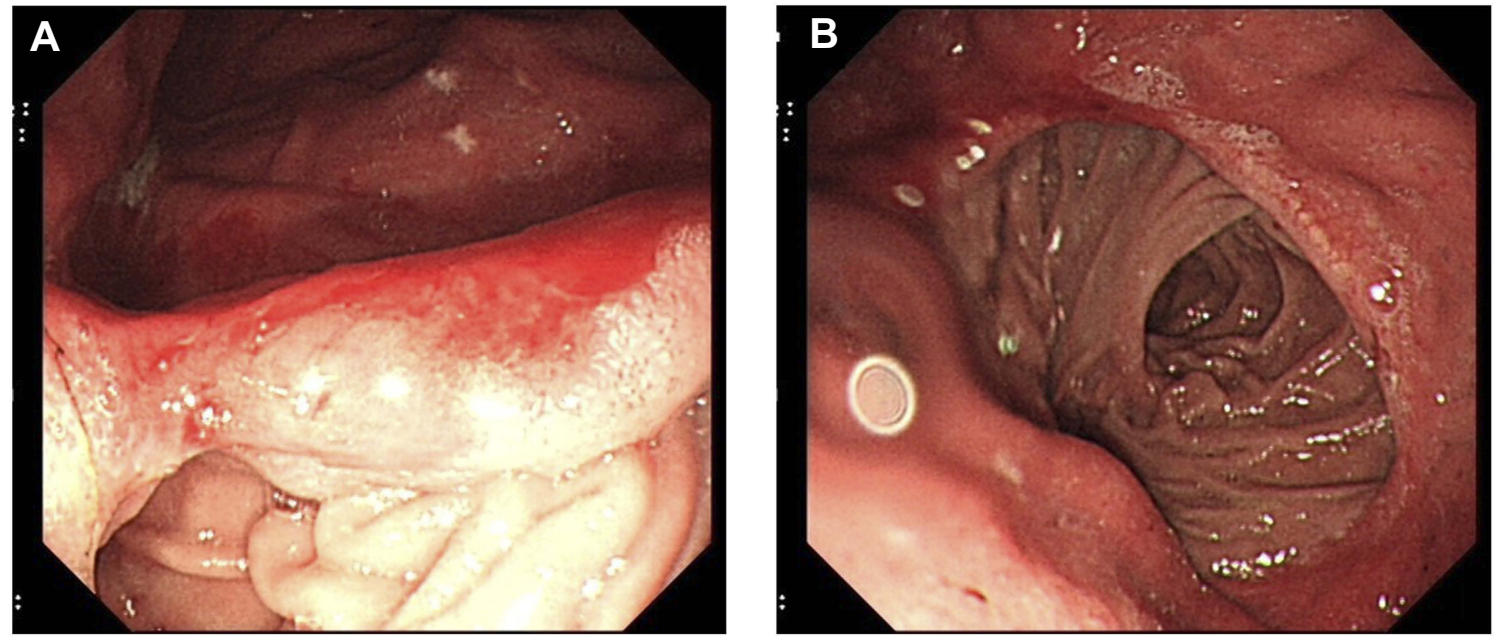

Figure 2 Gastroscopy showed anastomotic inflammation (A) and post-gastrectomy (Billroth II) (B) before duplication cysts resection.
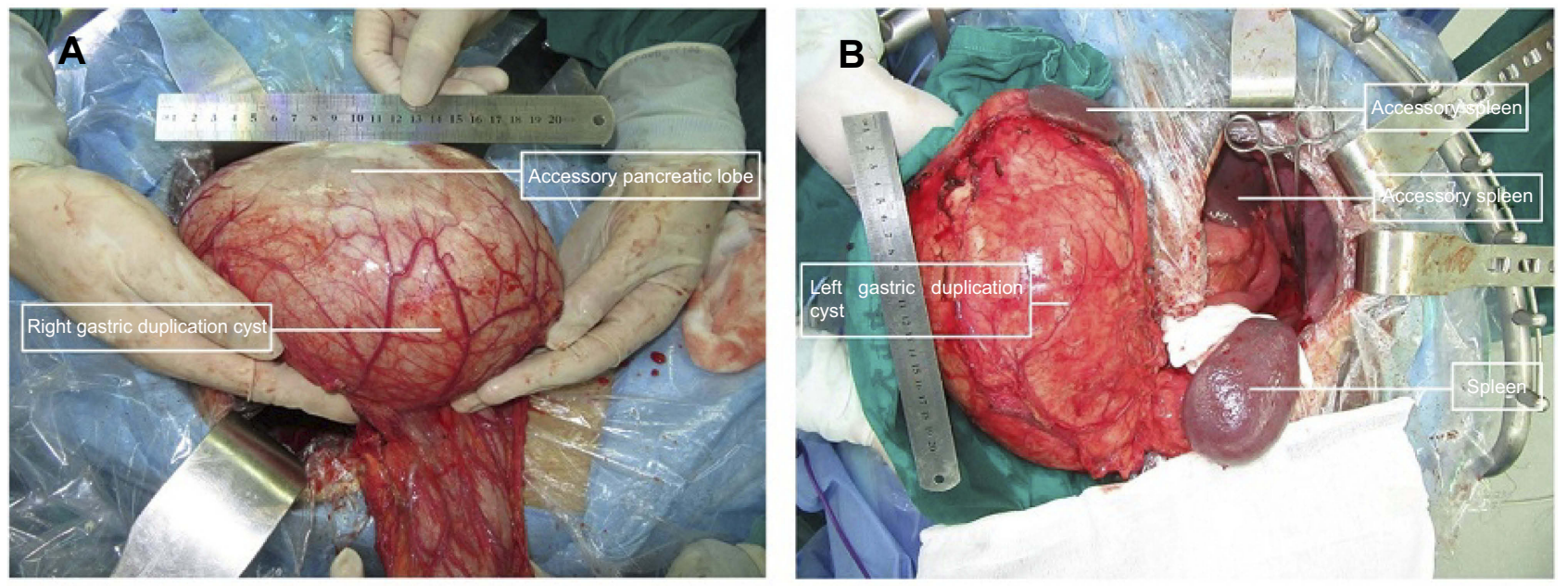

Figure 3 (A) The right duplication cyst and the accessory pancreatic lobe during operation; (B) the left duplication cyst and the accessory spleens. 
accessory spleen. The blood supply of these two spleens arose from the splenic artery. As these two spleens adhered tightly to the left retroperitoneal lesion, they were both resected. The accessory spleen was left. An accessory pancreatic lobe was also attached to the right duplication cyst but did not communicate with the duplication cyst. During surgical exploration, the liver, gallbladder, small intestine, colon and rectum were normal, without any evidence of carcinomatosis, ascites or metastasis. After the surgery, specimens were sent to the pathological department for further analysis. The final pathological results demonstrated that the right lesion was a $16 \times 11 \times 8$ $\mathrm{cm}$ cyst with pyloric and fundus epithelium. The left lesion was a $20 \times 19 \times 9.5-\mathrm{cm}$ cyst with pyloric epithelium and smooth muscle (Figure 5). No communication between the duplication cysts and stomach was found, while the aberrant pancreatic lobe communicated with duplication cysts with ductal system. The different level of amylase and characteristics of the liquid also confirmed this communication. The amylase of liquid inside was $438 \mathrm{U} / \mathrm{L}$ in the right cyst and $150 \mathrm{U} / \mathrm{L}$ in the left cyst. The liquid in the right cyst was clear while the liquid was similar to digestive juice in the other cyst. The cyst in sigmoid mesocolon was mesothelial cyst with crystal liquid inside. The spleen and accessory spleen were confirmed to be splenic tissue. The pathological examination established the diagnosis of

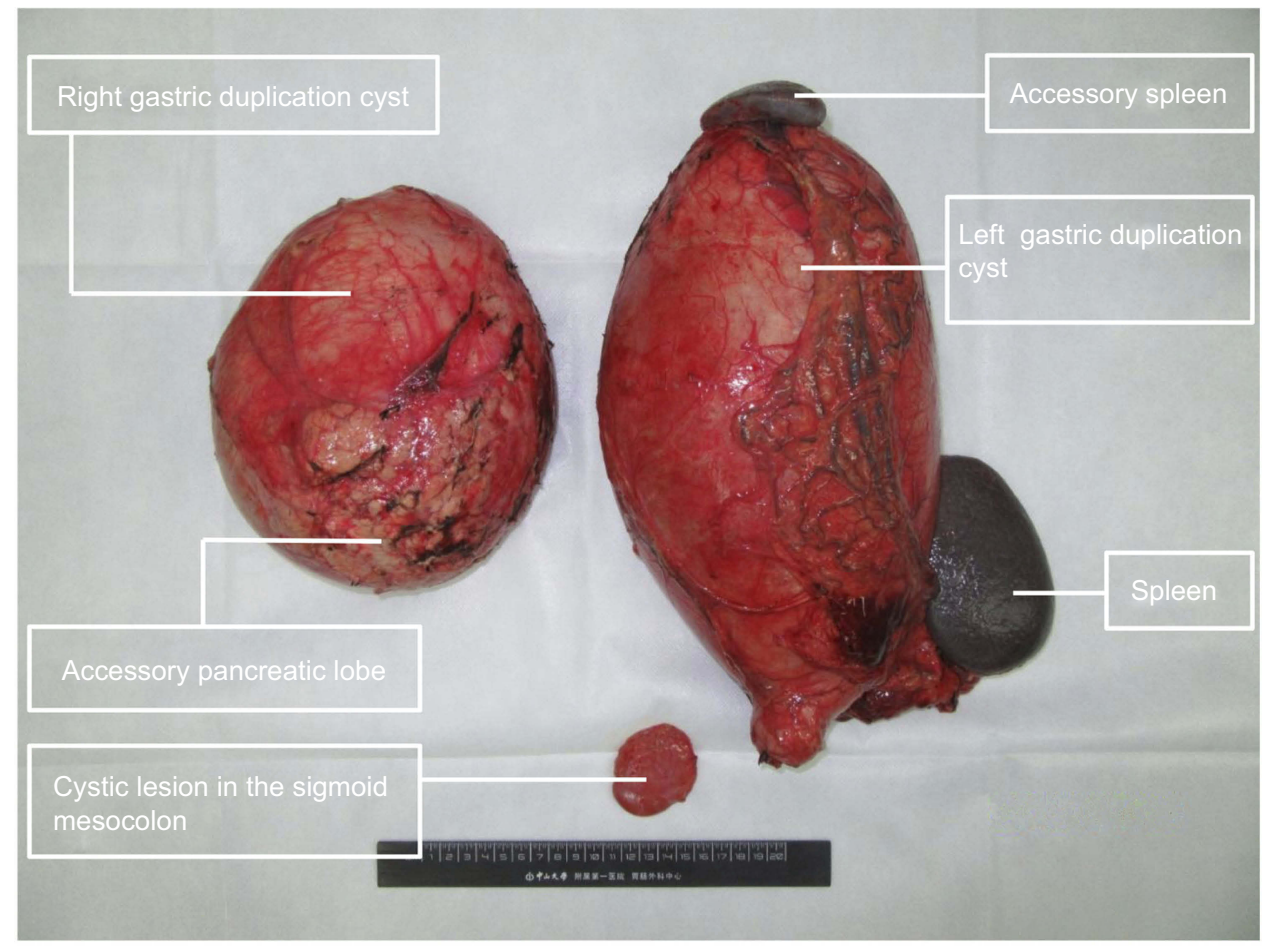

Figure 4 Two duplication cysts and the cystic lesion in the sigmoid mesocolon.
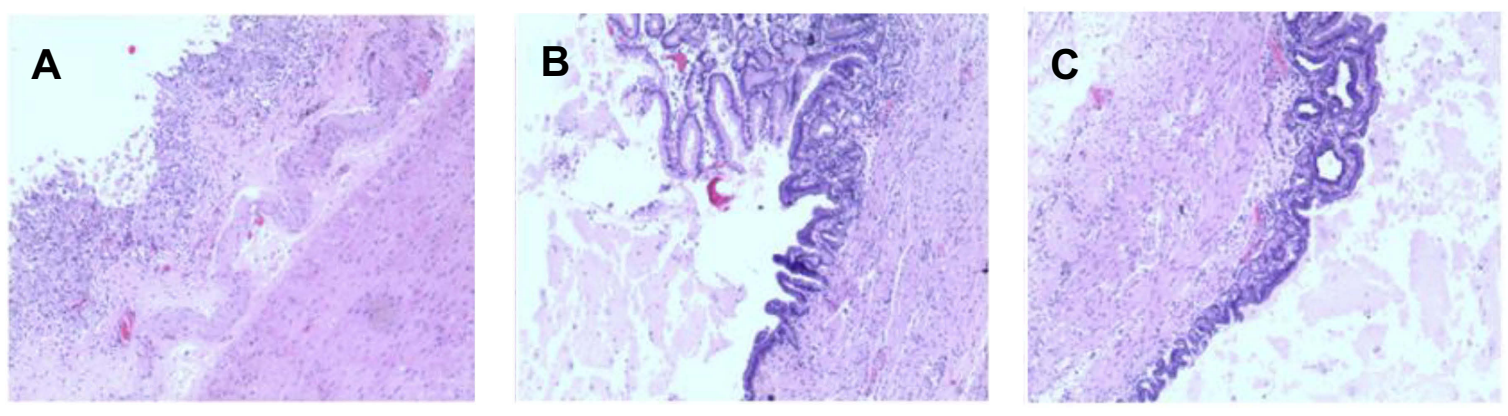

Figure 5 The pathological report confirmed the existence of gastric mucosa in the inner surface of the cysts. 
gastric duplication and polysplenia. A cinar and ductual elements were found in the accessory pancreatic lobe.

The patient had no surgical complications and was followed up for two years. CT scan showed no evidence of recurrence. The abdominal distention was relieved after the surgery.

This study was approved by the ethics review committee of the First Affiliated Hospital of Sun Yat-Sen University. Written informed consent was obtained from the patient for publication prior to this study.

\section{Discussion}

Duplication cysts of the alimentary tract are rare embryologic anomalies. The ileum and ileocecum were the most commonly affected, whereas gastric duplication cyst is highly uncommon with an incidence of 4-8\% among all alimentary duplication cysts. ${ }^{1-3}$ Most gastric duplication cysts occur in the greater curvature of the stomach. The diagnosis of gastrointestinal duplications should meet the following criteria: (1) hese duplications are spherical structures located in any part of the alimentary tract; (2) their inner surtface is lined by typical alimentary mucosa; (3) at least one coat of smooth muscle with muscularis propria surrounds the duplication cysts. The pathological examination in our case confirmed the existence of gastric mucosa and smooth muscle.

Gastrointestinal duplication can be divided into two types according to communication with the alimentary tract. The noncommunicating type accounts for about $80 \%$ of duplication cyst, while the communicating type having one communication is usually tubular. Those with proximal and distal communications are complete duplications. ${ }^{1}$

Many theories suggested that embryonic anomaly leads to duplication cyst. The most widely held explanations are Bremer's errors of recanalization and McLetchie's neuroenteric band theory. ${ }^{4,5}$ Bremer suggested that the recanalization and fusion of longitudinal folds allowing the passage of a bridge of submucosa and muscle is the origination of duplication cysts, which may happen at the early stage of intrauterine life. McLetchie suggested that notochordal and embryonic endodermal adhension gives rise to neuroenteric band, which may not elongate as quickly as its surrounding structures, causing traction diverticulum leading to duplication cyst formation. But there is still no theory satisfactory for explaining the development of gastrointestinal duplication.

The clinical symptoms of gastric duplication are usually nonspecific, such as nausea, vomiting, abdominal pain, palpable abdominal mass, weight loss and failure to thrive. ${ }^{4,5}$
Occasionally, some symptoms including gastrointestinal bleeding, peritonitis or even malignancy may be seen. Some cases had carcinomas arising from gastric duplication cysts, especially in middle-aged adults. ${ }^{6-12}$ According to these cases, no primary tumor was found. Adenocarcinoma is the most common pathological type of cancer arising from gastric duplication. Other types include epithelial or squamous cell carcinoma and neuroendocrine carcinoma. If the cyst ruptured during surgery, it may cause incomplete removal leading to peritoneal metastasis adenocarcinoma. Therefore, gastric duplication cysts should be resected completely even though their symptoms are similar to those of benign cysts. ${ }^{13}$ In our case, no abdominal malignancy was found. The patient was instructed to follow up for two years and no recurrence or cancer was found. No positive result was found in stool routine and fecal occult blood test. Therefore, complete resection is the recommended treatment for gastric duplication.

As the symptoms were not specific, abdominal CT or (MRI seems to be necessary in the diagnosis of duplication cyst. But misdiagnosis rate may reach up to $70 \% .{ }^{14}$ The variable content in these cysts mainly caused the misdiagnosis. In recent years, new techniques, such as endoscopic ultrasound-guided fine-needle aspiration showed security and better accuracy in the diagnosis of duplication cysts. ${ }^{15}$

About $50 \%$ of patients with gastric duplication had other congenital abnormalities, such as duplication or atresia in other parts of the alimentary canal, esophageal or duodenal diverticula. But coexistence of accessory pancreatic lobe was rare. Since the first case reported in 1959, only 29 cases have been reported until now. ${ }^{2,16-38}$ In these cases, about $82.7 \%$ of patients had recurrent abdominal pain caused by pancreatitis. The majority of these cases were females $(68.9 \%)$ with the average age of 16 years, but pancreatitis was not associated with gender or age. Recurrent pancreatitis occurred if gastric duplication was contiguous with the stomach. ${ }^{31,32}$ The reasons of pancreatitis were ulcer bleeding into the pancreatic duct caused by parietal cells and pancreatic duct retarding flow and obstruction caused by secretions of the ectopic mucosa. In our case, the accessory pancreas contiguous with right duplication cyst containing amylase-rich liquid, but no symptom of pancreatitis was found because no contiguity was found between stomach and duplication cysts. The amylase of serum and drainage liquid of abdominal cavity examined after operation were higher than normal values. But this also can be caused by the operation. If we had examined the serum amylase before surgery, it can be 
more reliable. McLetchie's theory fits the gastric duplication with accessory pancreatic lobe because the traction on the pancreatic duct by a neuroenteric band can produce both gastric and pancreatic abnormalities.

As polysplenia was also found in this case, another explanation for causes of accessory pancreatic lobe is polysplenia. Polysplenia is an anomaly formed by two or more splenuncules. Compared with less cases of coexistence of polysplenia and gastric duplication, concurrent anomalies of the spleen and pancreas were often reported. ${ }^{39-42}$ These may be caused by the same embryological origin of both organs from the dorsal mesogastrium. The most typical example of this concurrent anomaly is polysplenia with a short pancreas.

Gastric duplication cysts, polysplenia and accessory pancreatic lobe are uncommon congenital anomalies. To the best of our knowledge, there are no published reports describing this anomaly.

Another characteristic of this case is distal gastrectomy history 20 years ago, which was confirmed by gastroscopy before surgery (Figure 2). Most of the gastric duplications are diagnosed during the early years of life. But these cysts were neither found nor resected by doctors in previous gastrectomy. Since gastric duplication is a congenital disease, these lesions may exist at that time. But they may be too small to attract the surgeon's attention. Their size increased with age. Another explanation is that the duplication cysts were not congenital and developed after surgery. Gastric duplication can cause gastrointestinal bleeding because ectopic gastric mucosa can secret acid to cause ulceration. As this patient had gastric ulcer 20 years ago and had melena this time, the possibility of congenital duplication cyst was more reliable. These duplication cysts were congenital and ignored in the first operation. To the best of our knowledge, this is the first post-gastrectomy duplication of stomach case ever reported.

The recommended treatment for gastric duplication is complete resection. The gastric duplication without symptom is also considered to be excised to avoid malignant transformation. Resection of the accessory pancreas and closure of the pancreatic duct are also needed for a gastric duplication contiguous to the accessory pancreas in order to avoid pancreatitis.

\section{Conclusion}

In summary, we report this case of gastric duplication with an accessory pancreatic lobe and polysplenia after distal gastrectomy 20 years ago in an adult man. No similar cases have been reported. Gastrointestinal duplication and other coexistent congenital abnormalities should be paid attention to. More accurate diagnostic techniques are needed and complete surgical resection is the recommended treatment.

\section{Abbreviation list}

CT, Computed tomography; MRI, Magnetic resonance imaging; EUS-FNA, endoscopic ultrasound-guided fineneedle aspiration.

\section{Consent for publication}

Written informed consents were obtained from the patient involved in this case.

\section{Ethics approval and consent to participate}

This study was approved by the ethics committee of the First Affiliated Hospital of Sun Yat-sen University.

\section{Author contributions}

YF, XHZ and CQC performed the operation; YF and XHZ drafted the manuscript and made the final revision; XHZ and JNY neatened the illustrations in the manuscript. All authors contributed to data analysis, drafting or revising the article, gave final approval of the version to be published, and agree to be accountable for all aspects of the work.

\section{Disclosure}

The authors report no conflicts of interest in this work.

\section{References}

1. Bhatti ZS, Anderson MA, Wasnik AP. Complete gastric duplication in an adult with associated anomalies. Clin Imag. 2016;40(2):244-246. doi:10.1016/j.clinimag.2015.11.016

2. Turkvatan A, Erden A, Turkoglu MA, Bostanci EB, Disibeyaz S, Parlak E. An unusual cause of recurrent pancreatitis: a gastric duplication cyst with an accessory pancreatic lobe. Turk $J$ Gastroenterol. 2015;25(1):199-202. doi:10.5152/tjg

3. Samona S, Berri R. A case report and review of the literature of adult gastric duplication cyst. Case Rep Surg. 2015;2015:1-3. doi:10.1155/ 2015/240891

4. Iyer CP, Mahour GH. Duplications of the alimentary tract in infants and children. J Pediatr Surg. 1995;30(9):1267-1270.

5. Passos ID, Chatzoulis G, Milias K, Tzoi E, Christoforakis C, Spyridopouos P. Gastric duplication cyst associated with ectopic pancreas: case report and review of the literature. Int J Surg Case Rep. 2017;31:109-113. doi:10.1016/j.jiscr.2017.01.033

6. Zheng J, Jing $\mathrm{H}$. Adenocarcinoma arising from a gastric duplication cyst. Surg Oncol. 2012;21(2):e97-e101. doi:10.1016/j.suronc.2012.03.002

7. Barussaud ML, Meurette G, Cassagnau E, Dupasc B, Le Borgne J. Mixed adenocarcinoma and squamous cell carcinoma arising in a gastric duplication cyst. Gastroenterol Clin Biol. 2008;32(2):188-191. 
8. Horne G, Ming-Lum C, Kirkpatrick AW, Parker RL. High-grade neuroendocrine carcinoma arising in a gastric duplication cyst: a case report with literature review. Int J Surg Pathol. 2007;15 (2):187-191. doi:10.1177/1066896906295777

9. MAYO HJ, McKEE EE, ANDERSON RM. Carcinoma arising in reduplication of the stomach (gastrogenous cyst): a case report. Ann Surg. 1955;141(4):550-555. doi:10.1097/00000658-195504000-00019

10. Kuraoka K, Nakayama $H$, Kagawa T, Ichikawa T, Yasui W. Adenocarcinoma arising from a gastric duplication cyst with invasion to the stomach: a case report with literature review. J Clin Pathol. 2004;57(4):428-431. doi:10.1136/jcp.2003.013946

11. Treiger M, Rubens J, Chindler J, et al. Stomach duplication. Report of a $2 \mathrm{~d}$ case in literature complicated by a peptic ulcer and malignant neoplasms. Hospital (Rio J). 1969;75(1):1-10.

12. Coit DG, Mies C. Adenocarcinoma arising within a gastric duplication cyst. J Surg Oncol. 1992;50(4):274-277.

13. Liu K, Lin X, Wu J, et al. Peritoneal metastatic adenocarcinoma possibly due to a gastric duplication cyst: a case report and literature review. $B M C$ Gastroenterol. 2014;14:48. doi:10.1186/1471-230X-14-48

14. Eloubeidi MA, Cohn M, Cerfolio RJ, et al. Endoscopic ultrasoundguided fine-needle aspiration in the diagnosis of foregut duplication cysts: the value of demonstrating detached ciliary tufts in cyst fluid. Cancer-am Cancer Soc. 2004;102(4):253-258.

15. Seijo RS, Larino NJ, Abdulkader NI, et al. Adult gastric duplication cyst: diagnosis by endoscopic ultrasound-guided fine-needle aspiration (EUS-FNA). Rev Esp Enferm Dig. 2008;100(9):586-590.

16. Jain AS, Patel AM, Jain SR, Thakkar A. Accessory pancreatic lobe with gastric duplication cyst: diagnostic challenges of a rare congenital anomaly. BMJ Case Rep. 2015;mar12 1:r2014207751. doi:10.1136/bcr-2014-207751

17. Mohamed S, Djuro K, Walid C, et al. Gastric duplication cyst with elevated amylase: an unusual presentation mimicking pancreatic cystic neoplasm. ACG Case Rep J. 2015;2(2):86-88. doi:10.14309/crj.2015.13

18. BRADBEER JW. An unusual foregut anomaly: an extragastric pouch communicating with the pancreatic duct. Br J Surg. 1959;46:603-605.

19. Katz W, Annessa G, Read RC. Gastric duplication with pancreatic communication. Presenting as pancreatitis. Minn Med. 1967;50 (8):1175-1179.

20. Akers DR, Favara BE, Franciosi RA, Nelson JM. Duplications of the alimentary tract: report of three unusual cases associated with bile and pancreatic ducts. Surgery. 1972;71(6):817-823.

21. Parker BC, Guthrie J, France NE, Atwell JD. Gastric duplications in infancy. J Pediatr Surg. 1972;7(3):294-298.

22. Rosenlund ML, Schnaufer L. Gastric duplication presenting as cyclic abdominal pain. Clin Pediatr (Phila). 1978;17(10):747-748, 753. doi:10.1177/000992287801701004

23. Schwartz DL, So HB, Becker JM, Schneider KM. An ectopic gastric duplication arising from the pancreas and presenting with a pneumoperitoneum. J Pediatr Surg. 1979;14(2):187-188.

24. Black PR, Welch KJ, Eraklis AJ. Juxtapancreatic intestinal duplications with pancreatic ductal communication: a cause of pancreatitis and recurrent abdominal pain in childhood. J Pediatr Surg. 1986;21(3):257-261.

25. BRUGSCH HG. Case records of the massachusetts general hospital. Case 17-1964. N Engl J Med. 1964;270:736-742. doi:10.1056/ NEJM196404022701411
26. Lavine JE, Harrison M, Heyman MB. Gastrointestinal duplications causing relapsing pancreatitis in children. Gastroenterology. 1989;97 (6):1556-1558.

27. Johnstone DW, Forde KA, Markowitz D, Green PH, Farman J, Markowitz M. Gastric duplication cyst communicating with the pancreatic duct: a rare cause of recurrent abdominal pain. Surgery. 1991;109(1):97-100.

28. Whiddon DR, Olutoye OO, Broderick TJ, et al. Recurrent acute pancreatitis caused by a gastric duplication communicating with an aberrant pancreas. Am Surg. 1999;65(2):121-124.

29. Muraoka A, Tsuruno M, Katsuno G, et al. A gastric duplication cyst with an aberrant pancreatic ductal system: report of a case. Surg Today. 2002;32(6):531-535. doi:10.1007/s005950200092

30. Spence RK, Schnaufer L, Mahboubi S. Coexistant gastric duplication and accessory pancreas: clinical manifestations, embryogenesis, and treatment. J Pediatr Surg. 1986;21(1):68-70.

31. Traverso LW, Damus PS, Longmire WJ. Pancreatitis of unusual origin. Surg Gynecol Obstet. 1975;141(3):383-386.

32. Longmire WJ, Rose AR. Hemoductal pancreatitis. Surg Gynecol Obstet. 1973;136(2):246-250.

33. Hoffman M, Sugerman HJ, Heuman D, Turner MA, Kisloff B. Gastric duplication cyst communicating with aberrant pancreatic duct: a rare cause of recurrent acute pancreatitis. Surgery. 1987;101 (3):369-372.

34. Moss RL, Ryan JA, Kozarek RA, Hatch EI. Pancreatitis caused by a gastric duplication communicating with an aberrant pancreatic lobe. $J$ Pediatr Surg. 1996;31(5):733-736.

35. Kathleen KC, Sam P, Charles P, Susan T, Edward Q. Duplicate pancreas meets gastric duplication cyst: a tale of two anomalies. Int J Surg Case Rep. 2013;4:735-739. doi:10.1016/j.ijscr.2013.05.005

36. Case records of the Massachusetts General Hospital. Weekly clinicopathological exercises. Case 48-1982. Recurrent pancreatitis in a four-year-old girl. $N$ Engl $J$ Med. 1982;307(23):1438-1443. doi:10.1056/NEJM198212023072308

37. Bearzi I, Ranaldi R, Brancorsini D, Feliciotti F, Guerrieri M. Gastric duplication communicating with a pancreatic duct. Report of a case. Ital J Gastroenterol. 1990;22(2):78-81.

38. Shinde T, Lindner J, Silverman J, Agrawal R, Dhawan M. Gastricduplication cyst with an aberrant pancreatic-ductal system: an unusual cause of recurrent abdominal pain. Gastrointest Endosc. 2009;69 (2):377. doi:10.1016/j.gie.2008.04.059

39. Kobayashi H, Kawamoto S, Tamaki T, Konishi J, Togashi K. Polysplenia associated with semiannular pancreas. Eur Radiol. 2001;11:1639-1641. doi:10.1007/s003300000757

40. Wainwright $\mathrm{H}$, Nelson M. Polysplenia syndrome and congeniital short pancreas. Am J Med Genet. 1993;47:318-320. doi:10.1002/ ajmg.1320470304

41. Herman TE, Siegel MJ. Polysplenia syndrome with congenital pancreas. Am J Roentgenol. 1991;156:799-800. doi:10.2214/ajr.156.4. 2003448

42. Hadar H, Gadoth N, Herskovitz P, Heifetz M. Short pancreas in polysplenia syndrome. Acta Radiol. 1991;32:299-301. 


\section{Publish your work in this journal}

Therapeutics and Clinical Risk Management is an international, peerreviewed journal of clinical therapeutics and risk management, focusing on concise rapid reporting of clinical studies in all therapeutic areas, outcomes, safety, and programs for the effective, safe, and sustained use of medicines. This journal is indexed on PubMed Central, CAS,
EMBase, Scopus and the Elsevier Bibliographic databases. The manuscript management system is completely online and includes a very quick and fair peer-review system, which is all easy to use. Visit http://www.dovepress.com/testimonials.php to read real quotes from published authors. 